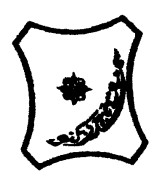

Bayero Journal of Pure and Applied Sciences, 8(2): 170 - 174

Received: September, 2015

Accepted: November, 2015

ISSN $2006-6996$

\title{
EFFECT OF ORAL ADMINISTRATION OF AQUEOUS LEAF EXTRACT OF MOMORDICA CHARANTIA (BITTER MELON) ON SERUM GLUCOSE, AND LIPID PROFILE IN ALLOXAN-INDUCED DIABETIC RATS
}

\author{
Sani, F. A., ${ }^{1}$ Atiku, M. K. ${ }^{2}$ and IMAM, A. A. ${ }^{2}$
}

${ }^{1}$ Department of Biochemistry, Faculty of Biomedical Science, Northwest University, Kano Nigeria. P.M.B

${ }^{2}$ Department of Biochemistry, Faculty of Biomedical Science,Bayero University, Kano Nigeria. P.M.B. 3011

*Corresponding Author: aaimam.bch@buk.edu.ng; Phone: 08052741302

\begin{abstract}
Momordica charantia (bitter melon) has been used extensively in herbal medicine as remedy for many disease conditions. The present study was undertaken to evaluate the effect of Momordica charantia (MC) aqueous leaf extract on serum fasting blood glucose (FBG) and lipid profile (total cholesterol TC, triglyceride TAG, high density lipoprotein HDL, low density lipoprotein LDL) in alloxan-induced diabetic rat. The extract was administered orally at the dose of $200 \mathrm{mg} / \mathrm{kg}, 400 \mathrm{mg} / \mathrm{kg}$, and $600 \mathrm{mg} / \mathrm{kg}$ body weight either for a period of 2 or 4 week. A significant $(p<0.05)$ improvement in the biochemical parameters such as FBG, TC, TAG, HDL, and LDL levels was observed in MC treated rats as compared to diabetic control rats. The response to treatment was gradual and dose-dependent with maximum effect at higher dose of $600 \mathrm{mg} / \mathrm{kg}$ body weight for 4 weeks.
\end{abstract}

Keywords: Momordica charantia, blood glucose, Lipid profile, Diabetes.

\section{INTRODUCTION}

Diabetes mellitus is considered as one of the five leading causes of death in the world (Joseph and Jini, 2011). Diabetes mellitus is a major global health concern with a projected rise in prevalence from 171 million in 2000 to 366 million 2030 (Shaw, et al., 2010). It is a syndrome of disordered metabolism, usually due to a combination of hereditary and environmental causes, resulting in abnormal high blood sugar levels (hyperglycemia) (Patel et al., 2012). Being a degenerative disease, diabetes is found in all parts of the world and it is becoming the third most lethal disease of mankind and increasing rapidly (Ogbonnia et al., 2008). It is the most common endocrine disorder, affecting 16 million individuals in the United States and as many as 200 million individuals worldwide (Shaw, et al., 2010). The prevalence rate of diabetes in Nigeria is estimated at $4.7 \%$ with rural areas having the lowest rates (Shaw, et al., 2010). The cure for diabetes is currently unknown, but could adequately be managed by the use of agents that exhibit hypoglycemic effect. The most popular and effective of such agents is insulin. A good number of oral hypoglycemic agents are also available, which include sulphonylureas, biguanides and alpha glucosidase inhibitors (Tunbrige and Home, 1991). However, majority of these hypoglycemic agents are either too expensive or their use is associated with some undesirable side effects and contraindications or both (Tunbrige and Home, 1991; Kameswara et al., 1999; Jaouhari et al., 2000). On the basis of these shortcomings and keeping in view the dangers associated with diabetic complications, some of which might result in premature death, the WHO study groups (WHO, 1985 \& 1994), recommended among other things the need for the development and evaluation of better, safe and affordable pharmacological agents. The report further recommended the evaluation of the efficacy of traditional medicine and other nonpharmacological methods in use for the management of the disease. In lieu of these recommendations, interest in fostering research on plant products and screening for agents with hypoglycemic agents is being pursued in various laboratories across the globe (WHO, 1985; 1994; Mei et al., 2005). Several medicinal plants have been used as dietary adjunct and in the treatment of numerous diseases without proper knowledge of their action. The multiple roles of wild traditional vegetables as both food and medicinal sources have widely been documented (Lee et al., 2003; Ogle et al., 2003; Adeboye and Opabode, 2004; Ayodele, 2005).

Mormodica charantia (Linn Family: Cucubaceae), also known as bitter melon, karela, pear, balsam pear, or bitter gourd, is a popular plant used for the treatment of many disease conditions amongst the indigenous population of Asia, South America, India, the Caribbean and East Africa (Cefalu et. al, 2008; Cousens 2008). Several studies have shown that bitter melon extract from the fruits, seeds, stem bark and leaves contain several bioactive compounds which could have pharmacological effects against many ailments such as hyperlipidemia, digestive disorder, microbial infections and menstrual problems in both animals and humans. (Wehash, et. al., 2012; Fuangchana et. al., 2011). Therefore, this present 
study was conducted to assess the antidiabetic effect

\section{METHODOLOGY}

\section{Experimental animals}

A total of 40 rats weighing $100 \mathrm{~g}$ to $140 \mathrm{~g}$ were obtained from animal house of Zoology Department, Bayero University, Kano. The rats were placed under standard condition and fed with standard (vital feed) diet and water ad libitum. The experiment was performed according to the principles of laboratory animal care.

\section{Collection and preparation of the plant extract}

Fresh leaves of Momordica charantia was obtained from Botany Department, Faculty of Science Bayero University, Kano-State, Nigeria, in the month of march, 2014, following identification by Botanist. The Leaves were air dried under shade and grounded into powder. The powder was weighed $(10 \mathrm{~g})$ and soaked in distilled water $(100 \mathrm{ml})$ for 48 hours. The mixture was filtered using whatman No.1 filter paper; the residue was dried and reweighed. The concentration of aqueous leaf extract (filtrate) was determined as the difference in weight/final volume of the solution using the relation,

Conc. $(\mathrm{g} / \mathrm{ml})=$

(Initial weight of sample - final weight of residue)

Final volume of the filtrate

The concentration of the aqueous leaf extract was found to be $135 \mathrm{mg} / \mathrm{ml}$. The volume of the extract to be administered was determined based on the weight of the rats and required dose, using the relation.

Volume administered $(\mathrm{ml})=$

Weight of rat $(\mathrm{kg}) \times$ Dose $(\mathrm{mg} / \mathrm{kg})$

Concentration of the filtrate $(\mathrm{mg} / \mathrm{ml})$

\section{Induction of diabetes mellitus}

Diabetes was induced using Alloxan monohydrate (Triverdi et al.,2004). Rats were allowed to fast for $24 \mathrm{hrs}$ after which they were administered with $100 \mathrm{mg} / \mathrm{kg}$ body weight of alloxan mononhydrate (Sigma, U.S.A.) intraperitoneally as a single dose to induce diabetes (Trivedi et al. 2004). Two days after the administration of alloxan, the fasting blood glucose levels of the rats were measured and rats with blood glucose level above $200 \mathrm{mg} / \mathrm{dl}$ were considered diabetic and were used for the experiments (Trivedi et al., 2004).

\section{Experimental design}

The experimental animals (40) were divided into eight groups of five rats each. Diabetes was induced in group II - VIII using alloxan as described above. Group I was the normal group neither induced with diabetic nor administered with the extract. Group II (Diabetic control) was induced with alloxn but not administered with the extract. Groups III, IV and V after induction with alloxan were administered with 200,400 and $600 \mathrm{mg} / \mathrm{kg}$ body weight of the extract of the leaf extract in alloxan-induced diabetic rats. respectively for 2 weeks, while groups VI, VII and VIII were also administered 200, 400 and $600 \mathrm{mg} / \mathrm{kg}$ body weight of the extract, respectively for 4 weeks after alloxan treatment.

\section{Experimental procedures}

Fasting blood glucose was determined using Glucometre (BG-102, Hangzhou Sejoy Electronic \&Co. Ltd, Zhejiang, China ). Serum Total cholesterol (CHOL) was determined using the method of Lothar et al., (1998). Triglycerides (TRIG), High density lipoprotein (HDL) and Low density lipoprotein (LDL) were determined by the method of Jacob et al., (1990). All these methods have been adopted from commercially available Randox Lipid profile diagnostic kits (Randox Laboratories Ltd, Antrim, United Kingdom) and all determinations were conducted following manufacturer's instructions.

\section{Statistical Analysis}

The data obtained was statistically evaluated using SPSS v. 20

RESULTS

Effect of Momordica Charantia aqueous leaf extract on fasting blood glucose (FBG)

The diabetic rats (Group II) showed significant increase in the FBG level $(P<0.05)$ when compared to the normal rats (Table 1 ). The administration of the $M C$ aqueous leaf extract in the diabetic rats reduced significantly $(p<0.05)$ the levels of FBG in the $2^{\text {nd }}$ and $4^{\text {th }}$ weeks post-treatment compared to the untreated diabetic control and the decrease was found to be dose dependent (Table 1 and 2). Two weeks administration of $\mathrm{MC}$ aqueous leaf extract compared with four weeks administration showed significant reduction $(P<0.05)$ in the mean serum levels of FBG (Table 3).

Effect of Momordica Charantia aqueous leaf extract on TC, TAG, HDL and LDL.

The diabetic rats (Group II) showed dose significant increase in the serum levels of total cholesterol TC, triglycerides TAG, low density lipoprotein LDL $(P<0.05)$, while serum level of high density lipoprotein $H D L$, reduced significantly $(P<0.05)$ as shown in Table 1. Administration of the MC aqueous extract for 2 and 4 weeks produced a significant $(p<0.05)$ dose-related reduction in TC, TAG, LDL and elevation in HDL levels (Table 1 \& 2). Two weeks administration of $M C$ aqueous leaf extract compared with four weeks adminstration (Table 3) shows significant decrease $(P<0.05)$ in the mean serum levels of TC, TAG, LDL. At daily dose of $400 \mathrm{mg} / \mathrm{kg}$ and $600 \mathrm{mg} / \mathrm{kg}$, mean serum level of HDL increases significantly $(P<0.05)$ when 2 weeks treatment was compared with four weeks treatment. 
Table 1: Serum levels of FBG and lipid Profile $(\mathrm{mg} / \mathrm{dl})$ two weeks after administration of different concentrations of MC aqueous leaf extract.

\begin{tabular}{llllll}
\hline Group & FBS $(\mathbf{m g} / \mathbf{d l})$ & TC(mg/dl) & TG(mg/dl) & HDL(mg/dl) & LDL(mg/dl) \\
\hline I (NC) & $88.40 \pm 2.88^{\text {abcd }}$ & $58.60 \pm 3.91^{\text {abcd }}$ & $45.20 \pm 4.40^{\text {abcd }}$ & $41.20 \pm 3.40^{\text {abcd }}$ & $8.36 \pm 2.17^{\text {abcd }}$ \\
II (PC) & $251.40 \pm 30.42^{\text {aghi }}$ & $144.80 \pm 14.48^{\text {aghi }}$ & $96.60 \pm 6.27^{\text {aghi }}$ & $25.80 \pm 4.21^{\text {afgh }}$ & $99.68 \pm 16.43^{\text {aghi }}$ \\
III & $202.60 \pm 5.03^{\text {bgmn }}$ & $94.60 \pm 6.44^{\text {bgmn }}$ & $79.00 \pm 8.34^{\text {bgn }}$ & $31.00 \pm 2.74^{\text {bf }}$ & $47.20 \pm 7.90^{\text {bg }}$ \\
IV & $187.80 \pm 3.56^{\text {chs }}$ & $83.20 \pm 4.44^{\text {chm }}$ & $67.60 \pm 6.07^{\text {chms }}$ & $31.00 \pm 2.54^{\text {cg }}$ & $38.68 \pm 6.80^{\text {ch }}$ \\
V & $157.00 \pm 10.37^{\text {dns }}$ & $82.00 \pm 7.07^{\text {din }}$ & $58.80 \pm 2.86^{\text {dins }}$ & $33.20 \pm 5.40^{\text {dh }}$ & $37.04 \pm 7.92^{\text {di }}$ \\
\hline
\end{tabular}

Key: NC: Negative control; PC: Positive control; MC: Mormodica charantia; FBS: Fasting blood sugar; TC: Total cholesterol; TG: Triglycerides; HDL: High density lipoprotein and LDL: Low density lipoprotein. Groups 1, II and III were administered 200,400 and $600 \mathrm{mg} / \mathrm{kg}$ body weight of the MC aqueous extract respectively. Values are presented as mean $\pm S D, n=5$. Figures bearing similar superscript in the same column are significantly different $(P<0.05)$.

Table 2: Serum level of FBG ( $\mathrm{mg} / \mathrm{dl})$, lipid Profile in $(\mathrm{mg} / \mathrm{dl})$ four weeks after treatment with different concentration MC aqueous leaves extract.

\begin{tabular}{|c|c|c|c|c|c|}
\hline Group & FBS (mg/dl) & $\mathrm{TC}(\mathrm{mg} / \mathrm{dl})$ & TG(mg/dl) & HDL(mg/dl) & LDL(mg/dl) \\
\hline $\mathrm{I}(\mathrm{NC})$ & $88.40 \pm 2.88^{\mathrm{ef}}$ & $58.60 \pm 3.91^{\mathrm{ef}}$ & $45.20 \pm 4.40^{e f}$ & $41.20 \pm 3.40^{\mathrm{ef}}$ & $8.36 \pm 2.17^{\text {ef }}$ \\
\hline II (PC) & $251.40 \pm 30.42^{\mathrm{jkl}}$ & $144.80 \pm 14.48^{\mathrm{jkl}}$ & $96.60 \pm 6.27^{\mathrm{jkl}}$ & $25.80 \pm 4.21^{\mathrm{jkl}}$ & $99.68 \pm 16.43^{\mathrm{jkl}}$ \\
\hline VI & $172.00 \pm 10.66^{\text {ejzâ }}$ & $81.20 \pm 5.61^{\mathrm{eju}}$ & $63.60 \pm 6.99^{\mathrm{ejv}}$ & $34.00 \pm 6.63^{\mathrm{ei}}$ & $34.48 \pm 9.74^{\text {ejxy }}$ \\
\hline VII & $136.00 \pm 6.63^{\mathrm{fkz} \tilde{b}}$ & $71.20 \pm 6.80^{\mathrm{fkv}}$ & $63.60 \pm 4.85^{\mathrm{fkw}}$ & $39.40 \pm 2.70^{j}$ & $25.20 \pm 5.70^{f k x z}$ \\
\hline VIII & $92.00 \pm 12.19^{\mathrm{lab}}$ & $58.80 \pm 4.15^{\text {luv }}$ & $58.80 \pm 7.35^{\mathrm{lvw}}$ & $33.20 \pm 4.39^{k}$ & $37.04 \pm 1.60^{\mathrm{lyz}}$ \\
\hline
\end{tabular}

Key: NC: Negative control; PC: Positive control; MC: Mormodica charantia; FBS: Fasting blood sugar; TC: Total cholesterol; TG: Triglycerides; HDL: High density lipoprotein and LDL: Low density lipoprotein. Groups VI,VII and VIII were administered 200, 400 and $600 \mathrm{mg} / \mathrm{kg}$ body weight of the MC aqueous extract respectively. Values are presented as mean $\pm S D, n=5$. Figures bearing similar superscript in the same column are significantly different $(P<0.05)$.

Table 3: Comparison between two and four weeks of serum level of FBG and lipid profile after treatment with different concentration of MC aqueous leaves extract.

\begin{tabular}{|c|c|c|c|c|c|}
\hline Group & FBS (mg/dl) & $\mathrm{TC}(\mathrm{mg} / \mathrm{dl})$ & TG(mg/dl) & HDL(mg/dl) & LDL(mg/dl) \\
\hline III & $202.60 \pm 5.03^{\mathrm{mnpgr}}$ & $94.60 \pm 6.44^{\mathrm{mnpgr}}$ & $79.00 \pm 8.34^{\mathrm{mnpgr}}$ & $31.00 \pm 2.7^{\mathrm{m}}$ & $47.20 \pm 7.90^{\mathrm{mnp}}$ \\
\hline IV & $187.80 \pm 3.56^{\mathrm{mstuv}}$ & $83.20 \pm 4.44^{\mathrm{ms}}$ & $67.60 \pm 6.07^{\mathrm{mst}}$ & $31.00 \pm 2.54^{\mathrm{np}}$ & $38.68 \pm 6.80^{q r}$ \\
\hline V & $157.00 \pm 10.37^{\text {nswy }}$ & $82.00 \pm 7.07^{\mathrm{nt}}$ & $58.80 \pm 2.86^{\text {nsu }}$ & $33.20 \pm 5.40^{q r}$ & $37.04 \pm 7.92^{\text {st }}$ \\
\hline VI & $172.00 \pm 10.66^{\text {ptwzâ }}$ & $81.20 \pm 5.61^{\mathrm{pu}}$ & $63.60 \pm 6.99^{p v}$ & $34.00 \pm 6.63$ & $34.48 \pm 9.74^{\mathrm{mu}}$ \\
\hline VII & $136.00 \pm 6.63^{q u \times z b}$ & $71.20 \pm 6.80^{\mathrm{qv}}$ & $63.60 \pm 4.85^{q w}$ & $39.40 \pm 2.70^{\text {nq }}$ & $25.20 \pm 5.70^{\text {nqsv }}$ \\
\hline VIII & $92.00 \pm 12.19^{\text {rvya } \tilde{b}}$ & $58.80 \pm 4.15^{\text {rstuv }}$ & $58.80 \pm 7.35^{\text {Irturw }}$ & $33.20 \pm 4.39^{\mathrm{mpr}}$ & $37.04 \pm 1.60^{\mathrm{prtv}}$ \\
\hline
\end{tabular}

Figures bearing similar superscript in the same column are significantly different $(\mathrm{P}<0.05)$.

\section{DISCUSSION}

Oral administration of MC leaf extract on daily basis for 2 to 4 weeks produced a dose-dependent significant decrease $(P<0.05)$ in fasting blood glucose $(F B G)$, total cholesterol (TC), triglycerides (TG), low density lipoprotein (LDL), while high density lipoprotein (HDL) increased significantly $(\mathrm{P}<0.05)$ compared to group II ( Table 1,and 2). These changes were significant different $(P<0.05)$ with 200,400 and $600 \mathrm{mg} / \mathrm{kg}$ body weight of the extract. Group VIII which recieved daily dose of $600 \mathrm{mg} / \mathrm{kg}$ body weight for 4 weeks did not show any significant difference $(P<0.05)$ in serum levels of FBG, TC, TAG, HDL and LDL compared to group I (Table 2). Therefore MC aqueous leaf extract administration for 2 to 4 weeks produced a dose dependent changes $(P<0.05)$.

The hypoglycemic effect of MC leaf extract recorded in this study is consistent with results of various previous studies (Virdi et al., 2003; Lotlikar and Rajarama 1966; Sathishsekar and Rajasekaran 2007; Miura et al., 2001) where with treatment with different parts of bitter melon plant lower glucose levels in animal and human experiments. The increase in cholesterol levels observed in diabetes mellitus is a consequence of accelerated fatty acid oxidation to acetylcoA which is involved in cholesterol synthesis (Adeneye and Olagunju, 2009). Since insulin/glucagon ratio is low in diabetes mellitus, the function of lipoprotein lipase in clearing VLDL-cholesterol from blood is compromised (Harris and Crabbs, 1982) and this leads to hypercholesterolemia. This certainly contributes to the development of cardiovascular disease. The serum level of fasting blood glucose, total cholesterol, triglycerides and LDL were significantly increased, and significant decreased in $\mathrm{HDL}(\mathrm{P}<0.05)$ with Alloxan induced diabetes in this study. These changes were significantly $(p<0.05)$ reversed by oral administration of MC aqueous leaf extract towards normal, with highest effect at a daily dose of $600 \mathrm{mg} / \mathrm{Kg}$ four weeks after treatment (Tables 1 and 2). This observations is also in consonant with various previous studies ( Chaturvedi et al., 2004; Chaturvedi 2005; Chen and Li 2005; Senanayake et al., 2004) where extracts from the different parts of Mormodica charantia such as root 
and stem bark were shown to significantly decrease Conclusion

From the results of this study, it is clear that Momordica charantia aqueous leaves extract has dose dependent anti-diabetic, hypolipidemic effects on

\section{References}

Adeboye, O. C. and Opabode, J. T. (2004). Status of conservation of the indigenous leaf vegetables and fruits of Africa. African Journal of Biotechnology, 3: 700-705.

Adeneye, A.A. , and Olagunju, J.A. (2009). Preliminary hypoglycemic and hypolipidemic activities of the aqueous seed extract of carica papaya Linn. In wistar rat. Biology and medicine, 1 (1) :1-10.

Ayodele, A.E. (2005). The medicinally important leafy vegetables of South Western Nigeria. Ethnobotanical leaflets. Available at: http://www.siu.edu/ ebl/leaflets/ayodele.ht $\mathrm{m}$. Assessed on 3rd July 2014.

Cefalu, W. T., Ye, J. and Wang, Z.Q. (2008). Efficacy of dietary supplementation with botanicals on carbohydrate metabolism in humans. Endocr Metab Immune Disorder Drugs Target, 8:78-81.

Chaturvedi, P., George, S.,Milinganyo, M., Tripathi Y. (2004). Effect of Momordica charantia on lipid profile and oral glucose tolerance in diabetic rats. Phytothera Res, 18: 954-56.

Chaturvedi, P. (2005). Role of Momordica charantia in maintaining the normal levelsof lipids and glucose in diabetic rats fed a high- fat and low-carbohydrate diet. $\mathrm{Br} J$ Biomed Sci; 62:124-26.

Chen, Q. and Li, E. (2005). Reduced adiposity in bitter melon (Momordica charantia) fed rats is associated with lower tissue triglyceride and higher plasma catecholamines. $\mathrm{Br} J \mathrm{Nutr}$, 93:747-54.

Cousens, G. (2008). There is a cure for diabetes: the tree of life 21day program. California: North Atlantic Books; p191-192.

Fuangchana, A., Sonthisombata, P., Seubnukamb, T., Chanouane, R., Chotchaisuwatd P. and Singulsatiene V. (2011). Hpoglycemic effect of bitter melon compared with metformin in newly diagnosed type 2 diabetes patients. $J$ Ethnopharmacol 134:422-428.

Harris, R.A. and Crabbs, D.W. (1982). Metabolic interrelationships. In: Text book of Biochemistry with clinical correlations. Ed. Delvin T.M., New York, John Wiley and Sons Inc. Pp 531-559.

Jacobs, D., Kasten, B.L., De Mott, W.R. and Wolfson, W.L. (1990). Laboratory and Test Handbook. Lexi-company Inc: Hudson (Cleveland) p. 219.

Jaouhari, J. T., Lazrek, H. B. and Jana, M. (2000). The hypoglycaemic activity of Zypoghyllum gaetulum extracts in alloxan-induced levels of lipid profile in diabetic animals. alloxan induced diabetic rats. Oral administration of MC aqueous leaves extract at a dose of $600 \mathrm{mg} / \mathrm{kg}$ for four weeks produce significant hypoglycaemic and hypolipidemic effect as seen in this study.

hyperglycaemic rats. Journal of Ethnopharmacology, 69: 17-20.

Joseph, B. and Jini D. (2011). Insight into the hypoglycemic effect of traditional Indian herbs used in the treatment of diabetes. Res J Med Plant 5(4):352-376.

Kameswara, B.R., Kesabulu, M. M., Giri, R. and Raoch, A. (1999). Antidiabetic and hypolipidaemic effects of Momordica cymbaleria Hook fruit powder in alloxan diabetic rats. Journal of Ethnopharmacology, 67: 103-109.

Kolawole O.T. and Ayankunle, A.A. (2012). Seasonal variation in the anti-diabetic and hypolipidemic effects of Momordica charantia fruit extract in rats. European Journal of medicinal plants. 2 (2): 177-185.

Lee, Y., Cesario, T., Wang, Y., Shanbrom, E. and Thrupp, L. (2003). Antibacterial activity of vegetables and juices. Nutrition, 19: 994191.

Lothar, T. (1998). Clinical Laboratory Diagnostic. $1^{\text {st }}$ edition TH-Books Verlagsgesellschaft $\mathrm{mbH}$, Frankfurt/ Main, Germany.pp.169.

Lotikar, M.M. and Rajarama, M.R. (1966). Pharmacology of hypoglycaemic principle isolated from the fruit of Momordica charantia Linn. Indian J Pharm 28:129132.

Mei, Y., Wei, D. and Liu, J. (2005). "Reversal of multidrug resistance in $\mathrm{KB}$ cells with tea polyphenol antioxidant capacity". Cancer Bio/Ther, 4: 468-73.

Miura, T.C., Itoh, N., Iwamoto, M., Kato, M., Kawai, S. R., Park, I.S. (2001). Hypoglycemic activity of the fruit of the Momordica charantia in type 2 diabetes in mice. J. Nutr. Sci. Vitaminol, 47, 240-344.

Odetola, A.A., Akinloye, O., Egunjobi, C., Adekunle, W. A., Ayoola, A., O. (2006). Possible antidiabetic and antihyperlipidemic effect of fermented parkia biglobosa (JACQ) extract in alloxan-induced diabetic rats. Clin. Exp. Pharmacol. Physiol. 33, 808-812.

Ogbonnia, S.O., Odimegu,J.I. and Enwuru, V.N. (2008). Evaluation of hypoglycemic and hypolipidemic effects of ethanolic extracts of Treculia Africana Decne and Bryopyllum pinntum Lam. and their mixture on steptozotocin (STZ) -induced diabetic rats. Afr J Biotech 7(15):2535-2539.

Ogle, B.M., Tuyet, H.T., Duyet, H.N., Xuan, D. and Nguyen, N. (2003). Food, feed or medicine: the multiple functions of edible wild plants in Vietnam. Economic Botany, 57: 103-117. 
Patel D.K., Prasad S.K., Kumar R. and Hemelatha S. (2012). An overview on antidiabetic medicinal plants having insulin mimetic property. Asian Pac J Trop Biomed 2:3 320330.

Sathishsekar, D., Rajasekaran, S. (2007). Protective role of Momordica charantia seeds extract on membrane bound ATPase and lysosomal hydrolases in rats with streptozotocin diabetes. J. Plant Sci., 2: 293-301.

Senanayake, G., Maruyama, M., Sakono, M. (2004). The effects of bitter melon (Momordica charantia) extracts on serum and liver lipid parameter in hamsters fed cholesterol-free and cholesterol-enriched diets. J Nutr Sci Vitaminol.; 50:253-57.

Shaw, J.E., Sicree, R.A. and Zimmet P.Z. (2010). Global estimates of the prevalence of diabetes for 2010 and 2030. Diabetes Research and Clinical Practices. 87: 4-14.

Trivedi N.A.; Mazumdar B.;Bhatti J.J.; and Hemavathi K.G.(2004). Effects of shilagit on blood glucose and lipid profile in alloxan induced diabetic rats.Indian Journal Pharmacol.,36:373-376.

Tunbridge, N.M.G. and Home, P. D. (1991). Diabetes and Endocrinology in Clinical Practice. Edward Arnold, London. Pp.1-133.

Virdi, J., Sivakami, S., Shahani, S., Suthar, A.C., Banavalikar, M.M., Biyani, M.K. (2003). Antihyperglycemic effects of three extracts from Momordica charantia . J Ethnopharmacol; 88:107-111.

Wehash F.E., Abpo-Ghanema II, Saleh R.M. (2012). Some physiological effects of Mormodica charantia and Trigonella foenum-graecum extracts in diabetic rats as compare with cidophage. World Academy of Science, Engineering and Technololgy 64:12061214.

WHO (1985). WHO study group on diabetes sssmellitus. WHO Geneva; 8-12 (WHO technical report series No. 727).

WHO (1994). WHO study group on diabetes mellitus. WHO Geneva (WHO technical report series No.

844). 